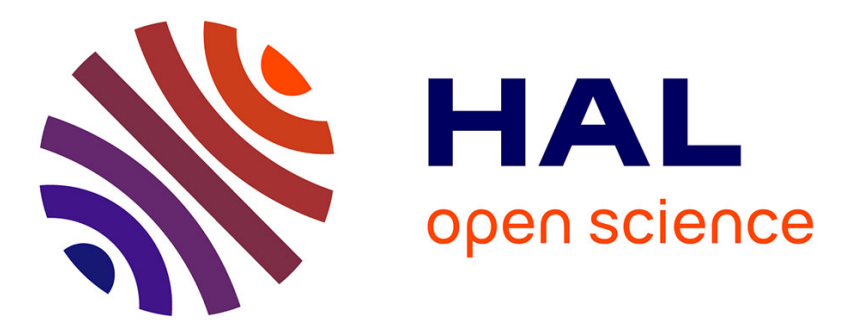

\title{
Consequences of antenna effects on s-SNOM imaging of a photonic mode
}

T Hannotte, Louis Thomas, C Nascimento Santos, M Lavancier, Sophie Eliet, B Walter, Marc Faucher, Jean-Francois Lampin, Romain Peretti

\section{- To cite this version:}

T Hannotte, Louis Thomas, C Nascimento Santos, M Lavancier, Sophie Eliet, et al.. Consequences of antenna effects on s-SNOM imaging of a photonic mode. Conference on Lasers and Electro-Optics, CLEO 2021, OSA, May 2021, San Jose (virtual), United States. pp.SW2K.5, 10.1364/CLEO_SI.2021.SW2K.5. hal-03313305

\section{HAL Id: hal-03313305 \\ https://hal.science/hal-03313305}

Submitted on 3 Aug 2021

HAL is a multi-disciplinary open access archive for the deposit and dissemination of scientific research documents, whether they are published or not. The documents may come from teaching and research institutions in France or abroad, or from public or private research centers.
L'archive ouverte pluridisciplinaire HAL, est destinée au dépôt et à la diffusion de documents scientifiques de niveau recherche, publiés ou non, émanant des établissements d'enseignement et de recherche français ou étrangers, des laboratoires publics ou privés. 


\title{
Consequences of antenna effects on s-SNOM imaging of a photonic mode
}

\author{
T. Hannotte ${ }^{1}$, L. Thomas ${ }^{1}$, C. Nascimento Santos ${ }^{1}$, M. Lavancier ${ }^{1}$, S. Eliet ${ }^{1}$, \\ B. Walter ${ }^{2}$, M. Faucher ${ }^{1}$, J.-F. Lampin ${ }^{1}$ and R. Peretti ${ }^{1}$ \\ ${ }^{l}$ Institut d'Electronique, de Microélectronique et de Nanotechnologie, CNRS, Univ. Lille, Villeneuve d'Ascq, \\ 59652 France \\ ${ }^{2}$ Vmicro SAS, Villeneuve d'Ascq, 59650 France \\ theo.hannotte@univ-lille.fr
}

\begin{abstract}
:
We report on the influence of antenna effects on the imaging by THz s-SNOM of a photonic mode. Unknown radiation pattern from the probe and sample combination makes the interpretation of a s-SNOM image non-trivial.
\end{abstract}

(C) 2020 The Author(s)

\section{Introduction}

Confinement of $\mathrm{THz}$ electric fields in small volumes is highly desired to investigate light-matter interactions at sub- $\lambda$ scales, typically $<100 \mu \mathrm{m}$ [1]. Split Ring Resonators (SRRs) are photonic devices concentrating electric field in their gap when their eigenfrequency is tuned to the incident radiation. The confinement in the gap of a $\mathrm{SRR}$, that can be as small as a few $100 \mathrm{~nm}$, can then provide $\mathrm{THz}$ sensing of a single nano object placed in the gap. However, direct characterization of confined THz photonic modes in the near-field (NF) at such scales remains limited. We studied here the NF distribution of SRRs by THz scattering Scanning Near-field optical Microscopy (s-SNOM) [2]. s-SNOM uses the apex of the tip of an Atomic Force Microscope (AFM) operating in intermittent contact mode as a nano-source and a nanoscatterer for the NF. This technique determines the NF distribution with a sub- $\lambda$ resolution while imaging the topography of the sample [3].

\section{Key elements design}

We first performed electromagnetic simulations to design SRRs tuned to the $2.5 \mathrm{THz}$ emission frequency of a $\mathrm{CO}_{2}$ pumped methanol gas laser. The chosen geometry consists of gold SRRs on crystalline quartz substrates $(19 \mu \mathrm{m}$ size, $200 \mathrm{~nm}$ thick, $2 \mu \mathrm{m}$ gap). Calculations predict the confinement of the electric field in the gap and its extension to the branches of the capacitive element atop the device (fig. 1a). We carried out s-SNOM experiments on the corresponding SRRs fabricated by e-beam lithography. Our setup operates in a homodyne detection scheme using probes designed for efficient collection and scattering of $\mathrm{THz}$ radiations.

The s-SNOM tip used for all the experiment was a Lprobe model 'CT' from Vmicro [4]. This probe is especially designed for THz s-SNOM experiment. In fact, Maissen et al. demonstrated that the imaging resolution can be greatly increased by using long and ultrasharp s-SNOM tips, and achieved resolution down to $15 \mathrm{~nm}$ [5]. Additionally, s-SNOM tip can be modeled as a dipole antenna excited by the near field concentration on the sample; hence, a longer tip (close to the excitation wavelength) will have a better scattering efficiency despite the small apex. The Lprobe aims at coping with these issues. In this work, the tip length is $70 \mu \mathrm{m}$, the cantilever stiffness is $40 \mathrm{~N} / \mathrm{m}$ and the resonant frequency of the fundamental mode measured in the complete neaSNOM setup is $280 \mathrm{kHz}$

\section{Results}

The THz s-SNOM images (fig. 1b) exhibited two distinct features : a bright region from the gap to the top branch of the capacitor corresponding to the photonic mode and an extinction of the optical signal on the bottom of the resonator. The topography showed no difference between these two regions (fig. 1c). If the computed NF accords well with the upper part of the experimental image, simulation does not account for the lower dark region.

To obtain a more reliable picture of the phenomena, we computed the far field emission of the scattered NF of the whole system, i.e. the AFM tip and the SRR, since both elements have dimensions comparable to the incident wavelength. We found that the position of the tip has a strong influence on the radiation pattern of the global system. When placed on the north (respectively south) branch, an emission lobe pointing south (respectively 

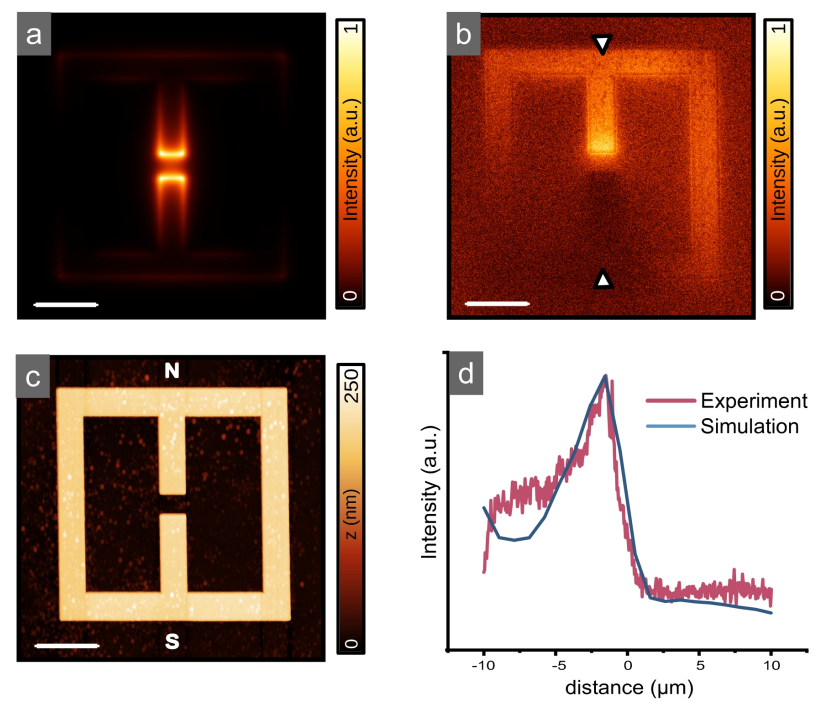

Figure 1. (a): Computed NF amplitude $250 \mathrm{~nm}$ atop the SRR (b): Typical THz s-SNOM image (demodulation at the 2nd harmonic of the probe oscillations) (c): Corresponding AFM Topography. Scale bar length is $5 \mu \mathrm{m}$. (d): Red line: $12 \mathrm{px}$ averaged section between the triangular cursors in (b), Blue line: computed intensity received at the location of the mirror at different positions of the tip in a similar geometry.

north) is generated. The scattered NF is only collected within the aperture of a parabolic mirror. Consequently, the north-pointing lobe of the radiation pattern is not detected. North and south orientations within our setup are labeled with respect to fig. 1c. This scenario accounts well for the asymmetry of the s-SNOM images and is in good agreement with the experimental data (fig. 1d).

This reasoning apply for any attempt at imaging a complex metallic structure with s-SNOM. Interpreting the SNOM signal to be an image of the local electric field relies on the implicit assumption that the emission pattern of the combination of the sample and the probe is independent of the probe position. Our experiment show that this assumption is wrong in the case of a SRR and should always be put to the test before carrying any interpretation of a SNOM picture.

\section{Summary}

To sum up, we imaged by THz s-SNOM the field confinement associated to the photonic mode of SRRs. The experiment were carried with full control over the SRRs and probe fabrications. The interpretation of the obtained images is non-trivial and strongly deviates from intuitive assumptions that the detected signal directly scales with the near-field intensity at the probe apex. The directivity of the antenna formed by the sample and the tip has a strong influence on the result. investigation on the far-field radiation pattern of the system is mandatory to deduce the near-field profile of a metallic structure from a SNOM measurement. We are now investigating new routes for THz s-SNOM to image the full NF distribution and aim to reduce gap size to achieve even narrower confinement.

\section{References}

1. G. Keiser and P. Klarskov, "Terahertz field confinement in nonlinear metamaterials and near-field imaging," Photonics 6, 22 (2019).

2. A. J. Huber, F. Keilmann, J. Wittborn, J. Aizpurua, and R. Hillenbrand, "Terahertz near-field nanoscopy of mobile carriers in single semiconductor nanodevices," Nano Lett. 8, 3766-3770 (2008).

3. X. Chen, D. Hu, R. Mescall, G. You, D. N. Basov, Q. Dai, and M. Liu, "Modern scattering-type scanning near-field optical microscopy for advanced material research," Adv. Mater. p. 1804774 (2019).

4. B. Walter, E. Mairiaux, D. Vignaud, S. Eliet, J. F. Lampin, and M. Faucher, "Terahertz near-field imaging using batch-fabricated cantilevers with $70 \mu \mathrm{m}$ long tips," in $201944^{\text {th }}$ International Conference on Infrared, Millimeter, and Terahertz Waves (IRMMW-THz), (IEEE, 2019).

5. C. Maissen, S. Chen, E. Nikulina, A. Govyadinov, and R. Hillenbrand, "Probes for ultrasensitive THz nanoscopy," ACS Photonics 6, 1279-1288 (2019). 